\title{
MicroRNA-9-5p downregulates Klf4 and influences the progression of hepatocellular carcinoma via the AKT signaling pathway
}

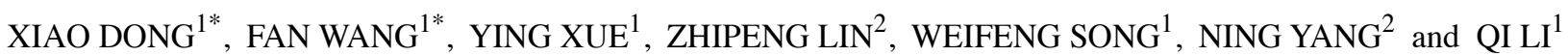 \\ ${ }^{1}$ Department of Oncology, Shanghai General Hospital, Shanghai Jiao Tong University School of Medicine, \\ Shanghai 200080; ${ }^{2}$ The 5th Department of Hepatic Surgery, Eastern Hepatobiliary Surgery Hospital, \\ The Second Military Medical University, Shanghai 200082, P.R. China
}

Received August 4, 2018; Accepted January 9, 2019

DOI: $10.3892 /$ ijmm.2019.4062

\begin{abstract}
Krüppel-like factor 4 (Klf4) is a transcriptional factor involved in the progression of hepatocellular carcinoma (HCC). However, the underlying regulatory mechanisms associated with the Klf4 gene as a tumor suppressor in HCC remain unclear. microRNAs (miRNAs or miRs) are a series of small non-coding RNAs that serve a vital role in regulating gene expression via their influence on protein translation and the associated degradation of mRNA. The mRNA expression levels of the miRNA, miR-9-5p, and Klf4 were measured using reverse transcription-quantitative polymerase chain reaction. The protein expression levels of Klf4, protein kinase B (AKT), phosphorylated (p-)AKT, mechanistic target of rapamycin (mTOR), p-mTOR, B cell lymphoma-2 (Bcl-2) and $\mathrm{Bcl}-2$-associated $\mathrm{X}$ protein (Bax) were determined by western blot analysis. Dual luciferase reporter assay was used to confirm a direct interaction between miR-9-5p and the 3'-untranslated region (3'-UTR) sequence of Klf4. Cell counting kit- 8 assay, wound healing assay, Transwell migration assay and flow cytometric analysis were performed to evaluate the proliferative, migratory and apoptotic capabilities of the HCC cells. In the present study, miR-9-5p was revealed to be overexpressed in HCC as a novel upstream gene of Klf4. miR-9-5p expression was inversely associated with Klf4
\end{abstract}

Correspondence to: Dr Qi Li, Department of Oncology, Shanghai General Hospital, Shanghai Jiao Tong University School of Medicine, 100 Haining Road, Shanghai 200080, P.R. China

E-mail: leeqi2001@hotmail.com

Dr Ning Yang, The 5th Department of Hepatic Surgery, Eastern Hepatobiliary Surgery Hospital, The Second Military Medical University, 225 Changhai Road, Shanghai 200082, P.R. China

E-mail: lancet00@163.com

${ }^{*}$ Contributed equally

Key words: hepatocellular carcinoma, Krüppel-like transcription factor 4, microRNA-9-5p, progression, protein kinase B pathway expression in clinical samples. Additionally, Kaplan-Meier analysis revealed a markedly poor prognosis of HCC in the miR-9-5p high-expression group. Bioinformatics analysis revealed that miR-9-5p bound directly to the 3'-UTR of Klf4, which reduced the expression levels of Klf4. The miR-9-5p/Klf4 axis promoted HCC proliferation and migration, and inhibited HCC apoptosis. Furthermore, miR-9-5p upregulated the Bcl-2/Bax protein ratio and activated AKT/mTOR signaling. Taken together, these data demonstrated that the miR-9-5p/Klf4 axis was able to promote HCC progression, which may occur via regulation of the AKT signaling pathway, highlighting a potential novel target in HCC treatment.

\section{Introduction}

Hepatocellular carcinoma (HCC) is one of the most common malignancies worldwide, particularly in developing countries (1). Surgical resection is an appropriate therapy for early HCC (2). However, the majority of patients are initially diagnosed with advanced HCC, and, combined with poor prognosis due to a high intrahepatic or extrahepatic metastatic potential, survival rates for patients remain low (3). It has been demonstrated that patients with advanced HCC could benefit from administration of molecular target drugs that target signaling cascades, such as the multikinase inhibitor, sorafenib (4). Numerous researchers are interested in the molecular targeted treatment field (5-7). Previous studies have demonstrated that several cell signaling pathways, including the Ras/Raf/mitogen-activated protein kinase kinase/extracellular signal-regulated kinase (8), Wnt/ $\beta$-catenin (9) and phosphoinositide 3-kinase (PI3K)/protein kinase B (AKT)/mammalian target of rapamycin (mTOR) (10) pathways, are involved in HCC occurrence and metastasis. Furthermore, it is noteworthy that AKT appears to be activated in $>50 \%$ cases of HCC occurrence (11).

The Krüppel-like factor (Klf) family is characterized by a highly conserved $\mathrm{C} 2 \mathrm{H} 2$ zinc finger motif, which consists of two cysteine and histidine residues (12). The protein family members combine with the target gene sequence that is complementary to the GC/GT/CACCC site, serving an important role in regulating specific gene transcription (13). 
The amino-terminal ends of the Klf family members all differ from each other, and they combine with various activating or inhibiting factors. This feature leads to the diversity of the Klf family members $(14,15)$. Klf4, also termed 'gastrointestinal concentration Klf', is predominantly expressed in gastrointestinal vascular endothelial cells (16). Klf4 contains five known AKT phosphorylation sites: Thr-399, Ser-19, Thr-33, Ser-234 and S326 (17), with the AKT pathway being the pathway that mediates the expression of the anti-apoptotic protein, B-cell lymphoma 2 (Bcl-2), and the apoptotic protein, Bcl-2-associated X protein (Bax) (18).

In various tumor types, Klf4 is considered to be a cancer suppressor protein that regulates various cell signaling pathways associated with a number of different processes: i) Epithelial-mesenchymal transition reversion (19); ii) the oncogenic transforming growth factor- $\beta /$ mothers against decapentaplegic homolog signaling pathway (20); iii) the PI3K/AKT/p21 pathway (21); and iv) the Bcl-2/Bax ratio (22). The present research group has previously reported that the deregulation of Klf4 is critical for loss of expression of the vitamin $D$ receptor, which enhances the invasive and metastatic potential of HCC (23). However, the molecular mechanisms that are associated with regulating low expression levels of Klf4 in HCC require further investigation.

microRNAs (miRNAs or miRs) are small, endogenous non-coding RNAs that are 22 nucleotides in length, which regulate gene expression through protein translation and the associated degradation of mRNA (24). miRNAs function as oncogenes or tumor suppressors, depending on the target gene concerned. For example, miR-373 increases proliferation of cervical cancer cells by directly targeting the highly conserved deubiquitinating enzyme of the ovarian tumor (otubain) family, YOD1 (25). miR-340, targeting Janus kinase 1, has been demonstrated to inhibit HCC proliferation and invasion (26). A study published previously by our research group revealed that Klf4 expression was decreased in $\mathrm{HCC}$, and that miR-135a-5p affected the expression of Klf4 (27).

In the present study, miRNA prediction bioinformatics analysis was used to demonstrate that miR-9-5p is a regulator of Klf4. miR-9-5p has a different stem-loop structure compared with the precursors of miR-9 (28). Overexpression of miR-9 has been demonstrated in HCC cells (29), whereas the expression levels of Klf4 are decreased (23). Therefore, the present study aimed to explore whether miR-9-5p is a functional target of the 3'-untranslated region (3'-UTR) of Klf4 in order to identify novel targets for HCC treatment.

To meet this aim, the expression levels of miR-9-5p and Klf4 were initially investigated in clinical samples, and overall survival (OS) rates of different levels of the miR-9-5p mRNA expression groups were analyzed in The Cancer Genome Atlas (TCGA) database. Subsequently, the evidence that miR-9-5p directly targeted Klf4 in HCC cells was corroborated. Further studies suggested that miR-9-5p downregulating Klf4, is involved in the HCC proliferation, apoptosis and migration of HCC cells, potentially resulting in activation of AKT pathway.

\section{Materials and methods}

Cell lines and culture. Human HCC cell lines (SK-Hep-1, HCC-LM3, Huh7 and Hep-3B), and the human immortalized liver cell line, L02, were purchased from Shanghai Cell Bank of the Chinese Academy of Sciences (Shanghai, China) and maintained in Invitrogen ${ }^{\circledast}$ Dulbecco's modified Eagle's medium (DMEM; Thermo Fisher Scientific, Inc., Waltham, MA, USA) supplemented with $10 \%$ Gibco $^{\mathrm{TM}}$ fetal bovine serum (FBS) and $100 \mathrm{U} / \mathrm{ml}$ penicillin/streptomycin (Thermo Fisher Scientific, Inc.) at $37^{\circ} \mathrm{C}$ in a humidified atmosphere containing $5 \% \mathrm{CO}_{2}$.

Clinical specimens. A total of $20 \mathrm{HCC}$ tissue and adjacent normal tissue samples were obtained from 20 patients at The 5th Department of Hepatic Surgery, Eastern Hepatobiliary Surgery Hospital, The Second Military Medical University (Shanghai, China) between March and July 2017. All patients with pathological diagnosis of primary HCC and clinical stage of I-III were included. The samples were snap-frozen in liquid nitrogen and stored at $-80^{\circ} \mathrm{C}$. The American Joint Committee on Cancer/International Union Against Cancer staging system for HCC was used to define the stage of patients $(30,31)$. The Ethics Committee of the hospital approved the present study, and patient consent was obtained prior to tissue collection. All samples following resection were immediately snap-frozen in liquid nitrogen, and subsequently stored at $-80^{\circ} \mathrm{C}$.

Klf4 overexpression plasmid, small interfering (si)RNA against Klf4 (siKlf4), miRNA mimic and inhibitor. The Klf4 overexpression Klf4 plasmid was obtained from the scientific research group of Professor Keping Xie (University of Texas, MD Anderson Cancer Center, Houston, TX, USA). siKlf4 (forward primer, 5'-AUCGUUGAACUCCUCGGUCUCUCU C-3'; reverse primer, 5'-GAGAGAGACCGAGGAGUUCAA CGAU-3') was synthesized by Shanghai GenePharma Co., Ltd. (Shanghai, China), as were miR-9-5p mimic (forward, 5'-UCUUUGGUUAUCUAGCUGUAUGA-3'; reverse, 5'-UUA GAAACCAAUAGAUCGACAUA-3'), miR-9-5p inhibitor (5'-UCAUACAGCUAGAUA ACCAAAGA-3'), miR-9-5p inhibitor negative control (NC; 5'-CAGUACUUUUGUGUA GUACAA-3'), mimic NC (forward, 5'-UUCUCCGAACGU GUCACGUTT-3'; reverse, 5'-ACGUGACACGUUCGGAGA ATT-3'), miR-128 mimic (forward, 5'-UCACAGUGAACC GGUCUCUUU-3'; reverse, 5'-AGAGACCGGUUCACGGUG AUU-3'), miR-449a mimic (forward, 5'-UGGCAGUGUAUU GUUAGCUGGU-3'; reverse, 5'-CAGCUAACAAUACAC UGCAAUU-3') and miR-214 mimic (forward, 5'-ACAGCA GGCACAGACAGGCAG-3'; reverse, 5'-GCCUG UCUGUGC CUGCUGUUU-3').

Cell transfection. A total of $2 \times 10^{5} \mathrm{HCC}$ cells per well were seeded in a 6-well plate prior to the day of transfection. When the cell density had reached $70-80 \%$ confluence, Klf4 overexpression plasmid, siKlf4, miR-9-5p mimic and miR-9-5p inhibitor were used for transfection with Lipofectamine ${ }^{\circledR} 2000$ transfection reagent (Thermo Fisher Scientific, Inc.) according to the manufacturer's protocol. DMEM without FBS was mixed with Lipofectamine ${ }^{\circledR} 2000$, mimic, inhibitor, siRNA or plasmid. They were incubated at room temperature for $30 \mathrm{~min}$. The mixture was added into cells. It was then incubated at $37^{\circ} \mathrm{C}$ and with $5 \% \mathrm{CO}_{2}$ for $48 \mathrm{~h}$. Transfection efficiency was verified using reverse transcription-quantitative polymerase chain reaction (RT-qPCR) and western blot analysis. Subsequent experiments were performed $48 \mathrm{~h}$ following transfection. 
Western blot analysis. HCC cells were lysed using radioimmunoprecipitation buffer containing protease inhibitors (Sigma-Aldrich; Merck KGaA, Darmstadt, Germany). Protein concentrations were determined using the bicinchoninic acid assay kit (Thermo Fisher Scientific, Inc.) according to the manufacturer's protocol. Subsequently, $25 \mu \mathrm{g}$ protein were resolved on 5 or $10 \%$ SDS-PAGE and transferred onto polyvinylidene difluoride membranes. The membranes were then treated with 5\% non-fat milk blocking solution for $2 \mathrm{~h}$ at room temperature, and incubated overnight at $4^{\circ} \mathrm{C}$ with the following primary antibodies (all Cell Signaling Technology, Inc., Danvers, MA, USA): Anti-Klf4 (cat. no. 4038; 54 kDa; rabbit polyclonal; 1:1,000), anti-AKT Ser-473 (cat. no. 4091; $56 \mathrm{kDa}$; rabbit polyclonal; 1:1,000), antibody phosphorylated (p)-AKT Ser-473 (cat. no. 4069; 56 kDa; rabbit polyclonal; 1:1,000), anti-Bcl-2 (cat. no. 15071; $26 \mathrm{kDa}$; mouse polyclonal; 1:1,000), anti-Bax (cat. no. 5032; $20 \mathrm{kDa}$; rabbit polyclonal; 1:1,000), anti-mTOR (cat. no. 2972; $289 \mathrm{kDa}$; rabbit polyclonal; 1:1,000), antibody p-mTOR (cat. no. 5536; 289 kDa; rabbit polyclonal; 1:1,000) and GAPDH (cat. no. 5174; $37 \mathrm{kDa}$; rabbit monoclonal; 1:5,000). Horseradish peroxidase (HRP)-conjugated goat anti-rabbit (cat. no. 7074) or anti-mouse (cat. no. 7076; both 1:10,000; Cell Signaling Technology, Inc.) was used as the secondary antibody and incubated at room temperature for $1 \mathrm{~h}$. Finally, the protein bands were detected using an enhanced chemiluminescence (ECL) western HRP substrate reagent (Thermo Fisher Scientific, Inc.) and images were captured using an Amersham Imager 600 System (GE Healthcare, Chicago, IL, USA). The band densitometry analysis was evaluated using ImageJ software, version 1.8.0 (National Institutes of Health, Bethesda, MD, USA).

$R T-q P C R$. Total RNA was extracted from the cultured cells and HCC tissue using TRIzol ${ }^{\circledR}$ reagent (Invitrogen; Thermo Fisher Scientific, Inc.) according to the manufacturer's protocol, and the concentration of RNA was measured using a NanoDrop 1000 spectrophotometer (Thermo Fisher Scientific, Inc., Wilmington, DE, USA). Total RNA was used to synthesize cDNA using a PrimeScript RT Reagent kit (Takara Bio, Inc., Otsu, Japan). The reverse transcription reaction conditions were as follows: $37^{\circ} \mathrm{C}$ for $30 \mathrm{sec}, 85^{\circ} \mathrm{C}$ for $30 \mathrm{sec}$ and $4^{\circ} \mathrm{C}$ at termination. qPCR was performed using a SYBR Prime Script $^{\mathrm{TM}}$ RT-qPCR kit (Takara Bio, Inc.), according to the manufacturer's protocol, and an ABI 7500 system (Applied Biosystems; Thermo Fisher Scientific, Inc.). The thermocycling conditions were as follows: Pre-denaturation at $95^{\circ} \mathrm{C}$ for $30 \mathrm{sec}$, followed by 40 cycles of denaturation at $95^{\circ} \mathrm{C}$ for $5 \mathrm{sec}$ and extension at $60^{\circ} \mathrm{C}$ for $30 \mathrm{sec}$. miDETEC A Track ${ }^{\mathrm{TM}}$ miRNA RT-qPCR Starter kit (Guangzhou RiboBio Co., Ltd., Guangzhou, China) was used to detect the expression level of miR-9-5p expression. The reverse transcription reaction conditions were as follows: $42^{\circ} \mathrm{C}$ for $1 \mathrm{~h}, 72^{\circ} \mathrm{C}$ for $10 \mathrm{~min}$ and $0^{\circ} \mathrm{C}$ at termination. qPCR thermocycling conditions were as follows: Pre-denaturation at $95^{\circ} \mathrm{C}$ for $10 \mathrm{~min}$, followed by 40 cycles of denaturation at $95^{\circ} \mathrm{C}$ for $10 \mathrm{sec}$ and extension at $60^{\circ} \mathrm{C}$ for $20 \mathrm{sec}$. U6 and GAPDH were used as internal controls for miRNA and gene expression, respectively. The primers used in the qPCR analysis were designed as follows: miR-9-5p, forward 5'-TCTTTGGTTATCTAGCTGTATGA-3' and reverse 5'-TTCCGCGGCCGCTATGGCCGACGTCGA
CGGGAATGGGGAAAGGGAA-3', Klf4, forward 5'-GTC TTGAGGAAGTGCTGAGC-3' and reverse 5'-ATCGTCTTC CCCTCTTTGGC-3'; U6, forward 5'-CTCGCTTCGGCA GCACA-3' and reverse 5'-AACGCTTCACGAATTTGCGT-3'; GAPDH, forward 5'-GCACCGTCAAGGCTGAGAAC-3' and reverse 5'-TGGTGAAGACGCCAGTGGA-3'. Expression levels were calculated using the $2^{-\Delta \Delta \mathrm{Cq}}$ method (32).

Dual-luciferase reporter assay. The binding site of miR-9-5p on Klf4 was identified using the bioinformatic tool, miRanda (http://www.microrna.org). The wild-type 3'-UTR, and mutation-type (MUT) 3'-UTR of Klf4 were cloned into the pGL3-basic promoter luciferase reporter vector (Promega Corporation, Madison, WI, USA). Prior to transfection, high-transfection-efficiency SK-Hep-1 cells were seeded at $2 \times 10^{5}$ cells per well in 6-well plates. Subsequently, transfection was performed with Lipofectamine ${ }^{\circledR} 2000$ transfection reagent (Thermo Fisher Scientific, Inc.). It was performed according to the experimental groups (WT-luc group, MUT-luc group, WT-luc + mimic NC group, MUT-luc + mimic NC group, WT-luc + miR-9-5p mimic group, MUT-luc + miR-9-5p mimic group). The Renilla luciferase plasmid (Promega Corporation) was co-transfected as a transfection efficiency control. Cells in 1xPLB lysis buffer were harvested $48 \mathrm{~h}$ following transfection, and Firefly and Renilla luciferase activities were quantified and normalized using a dual-Glo ${ }^{\circledR}$ Luciferase Assay system (Promega Corporation) according to the manufacturer's protocol.

Cell proliferation assay. Transfected cells were seeded at a density of 2,000 cells in $100 \mu \mathrm{l} /$ well in 96-well plates, and maintained in culture medium. Cell counting Kit-8 (CCK8; Beyotime Institute of Biotechnology, Haimen, China) solution $(10 \mu \mathrm{l})$ was added to each well, and cells were incubated at $37^{\circ} \mathrm{C}$ for $2 \mathrm{~h}$. The absorbance was subsequently read at $450 \mathrm{~nm}$ using an ELISA reader. This experiment was performed daily on days 1-5 following transfection.

Apoptosis determined by flow cytometric analysis. At least 10,000 transfected cells were counted in the treatment group (SK-Hep-1 cells: Control group, mimic group, Klf4 group, mimic-Klf4 group and HCC-LM3 cell: Control group, inhibitor group, siKlf4 group, inhibitor-siKlf4 group; SK-Hep-1 cells: Control group, mimic group, AKT inhibitor group, mimic-AKT inhibitor group and HCC-LM3 cell: Control group, inhibitor group, AKT inhibitor group, inhibitor-AKT inhibitor group). Transfected cells were washed twice with ice-cold water, and stained with $5 \mu \mathrm{l}$ annexin V-fluorescein isothiocyanate for $15 \mathrm{~min}$ and $1 \mu \mathrm{l}$ propidium iodide (PI; $1 \mathrm{mg} / \mathrm{ml}$ ) for $5 \mathrm{~min}$ at room temperature, the mixture was then incubated at room temperature for $30 \mathrm{~min}$, and subjected to analysis on a flow cytometer (FACS Calibur; BD Biosciences, San Jose, CA, USA). Results were analyzed using FlowJo v10 software (Tree Star, Inc., Ashland, OR, USA).

Inhibitor assay. AKT inhibitor (MK-2206,2 HCl; Selleck Chemicals, Houston, TX, USA) was used in subsequent cell proliferation and apoptosis assays, and purchased from. It was diluted in DMSO resulting in a final concentration of $10 \mu \mathrm{M}$. 
Cell migration assay. Transfected cells were digested into a single cell suspension using $0.25 \%$ trypsin-0.02\% EDTA solution in serum-free medium, and $2 \times 10^{4}$ cells were seeded into the upper chamber of 24-well Transwell plates (aperture size, $8 \mu \mathrm{m}$; EMD Millipore, Billerica, MA, USA) in $100 \mu \mathrm{l}$ medium. FBS culture medium $(10 \% ; 700 \mu \mathrm{l})$ was added to the lower chamber, and the cells were incubated at $37^{\circ} \mathrm{C}$ for $24 \mathrm{~h}$. The upper cells were removed with a cotton swab, while the lower cells were fixed in $4 \%$ formaldehyde for $30 \mathrm{~min}$ at room temperature. Following washing twice with PBS $(1 \mathrm{ml})$, the cells that had migrated into the lower chamber were stained with $0.05 \%$ crystal violet for $30 \mathrm{~min}$ at room temperature. Finally, three fields were randomly selected and images were captured following air-drying under light microscopy (magnification, x200).

Wound healing assay. SK-Hep-1 and HCC-LM3 cells were transfected as indicated in the figures (SK-Hep-1 cells: Control group, mimic group, Klf4 group, mimic-Klf4 group; and HCC-LM3 cells: Control group, inhibitor group, siKlf4 group, inhibitor-siKlf4 group). Following reaching $90 \%$ confluence in 24-well plates, a wound was made in the cell culture using a $10-\mu 1$ pipette tip, and images of the closure of the wound were captured at 0,24 and $48 \mathrm{~h}$ under light microscopy (magnification, x100).

Statistical analysis and data profile. GraphPad Prism 6.0 (GraphPad Software, Inc., La Jolla, CA, USA) and SPSS 20.0 software (IBM Corp., Armonk, NY, USA) were used for statistical analysis. Comparisons between two groups were performed using two-tailed, independent Student's $\mathrm{t}$-test in cell experimental data processing, whereas a paired Student's t-test was used in clinical data analysis. Differences among three or more groups were performed using one-way analysis of variance followed by the Student-Newman-Keuls post hoc test. TargetScan (http://www.targetscan.org/vert72/), miRNAmap (http://mirnamap.mbc.nctu.edu.tw/), and miRanda (http://www.microrna.org) were used to predict the miRNA candidates binding to Klf4. TCGA HCC miRNA database was downloaded (https://portal.gdc.cancer.gov/). A total of 267 records were available in TCGA database. Records with missing clinical information were excluded, thus 224 individuals were included in the analysis. For correlation of miR-9-5p and Klf4 expression, the data was analyzed using Spearman's correlation. Patient survival was evaluated using the Kaplan-Meier method and log-rank tests. Data are presented as the mean \pm standard error of the mean. $\mathrm{P}<0.05$ was considered to indicate a statistically significant difference.

\section{Results}

miR-9-5p overexpression downregulates Klf4 expression in $H C C$. Several miRNA candidates, including miR-26b-5p, miR-214-3p, miR-375, miR-449a, miR-9-5p, miR-107, miR-206, miR-128 and miR-367, which were predicted to bind to Klf4 using prediction websites, TargetScan, miRNAmap, and miRanda were selected. Among these miRNA candidates, miR-26b-5p (33), miR-367 (34), miR-107 (16), miR-375 and miR-206 (35) have been previously reported to regulate Klf4 (Fig. 1A); therefore, these miRNAs were not investigated further in the present study. It was revealed that miR-9-5p mimic markedly reduced the mRNA expression level of Klf4, suggesting that it may be critical for the expression of Klf4 (Fig. 1B). Subsequently, the mimics of the remaining miRNAs' mimics were transfected into Hep-3B cells (Fig. 1C). The results revealed that miRNA levels of miR-9-5p, miR-128, miR-449a and miR-214 were significantly increased following transfection with their respective mimics.

miR-9-5p overexpression in clinical samples is associated with low expression of Klf4 and poor prognosis for HCC. Expression levels of Klf4 and miR-9-5p expression in tumor and paired adjacent normal tissues in 20 patients were subsequently compared. These results revealed that the miRNA level of miR-9-5p was significantly increased in $75 \%$ of the HCC tissues $(15 / 20)$, whereas the mRNA level of Klf4 was downregulated in $70 \%$ of the tumor samples (14/20; Fig. 2A and B). Spearman's correlation indicated that miR-9-5p expression was moderately inversely correlated with Klf4 expression in these 20 paired specimens, a result that may have been influenced by the small sample size (Fig. 2C). The correlation between miR-9-5p and Klf4 expression, and clinicopathological features of the two groups was subsequently analyzed. These results demonstrated that there were no significant differences in miR-9-5p or Klf4 expression associated with age, sex, tumor size, grade or microvascular invasion (Table I). Follow-up evaluations did not identify any patients who had progressive diseases. Therefore, the TCGA HCC database was consulted, and relevant miRNA-sequencing data were downloaded.

Following separating the data by the median value, a significant difference was revealed to exist between the high and low miR-9-5p expression groups (Fig. 2D). The correlation between miR-9-5p expression and clinicopathological features of the two groups was subsequently analyzed. These results demonstrated that no significant differences existed between the expression groups in terms of age, sex, $\alpha$-fetoprotein, pathological stage or vascular invasion (Table II). The 5-year survival rate was $71.8 \%$ in the high miR-9-5p expression group, and $80.2 \%$ in the low miR-9-5p expression group (Table III). Kaplan-Meier analysis revealed an improved OS rate in the low miR-9-5p expression group compared with the high miR-9-5p expression group (Fig. 2E).

miR-9-5p directly targets the transcription factor Klf4 in HCC cells. Expression levels of Klf4 and miR-9-5p were detected by RT-qPCR in L02 cells and the four HCC cell lines. The results revealed that Klf4 was expressed at a lower level in HCC cells compared with L02 cells (Fig. 3A). By contrast, miR-9-5p was more highly expressed in HCC cells (Fig. 3B). Subsequently, the effects of miR-9-5p mimic and inhibitor on Klf4 mRNA and protein expression were investigated. Transfection efficiency was verified by RT-qPCR analysis (Fig. 3C). The Klf4 expression level was decreased in the HCC cells upon transfection with the miR-9-5p mimic, whereas the mRNA and protein expression levels were both increased following transfection with miR-9-5p inhibitor (Fig. 3D and E). To confirm whether miR-9-5p directly bound to Klf4, bioinformatics analysis was utilized (in miRanda) to predict the potential binding site of miR-9-5p to the 3'-UTR of Klf4. The corresponding wild-type and mutation type Klf4 3'-UTRs were constructed, 
A

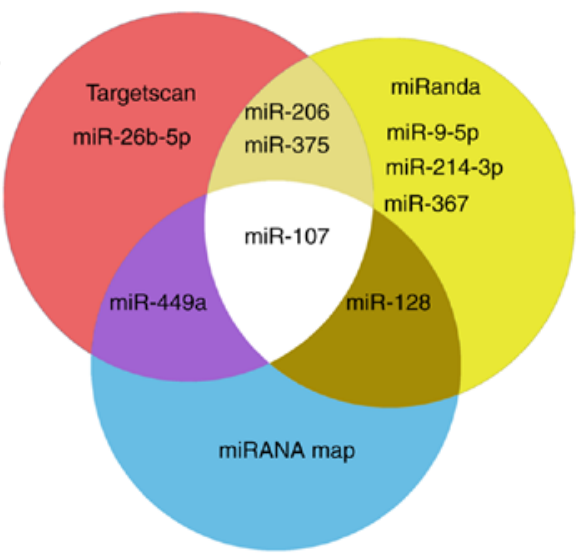

C
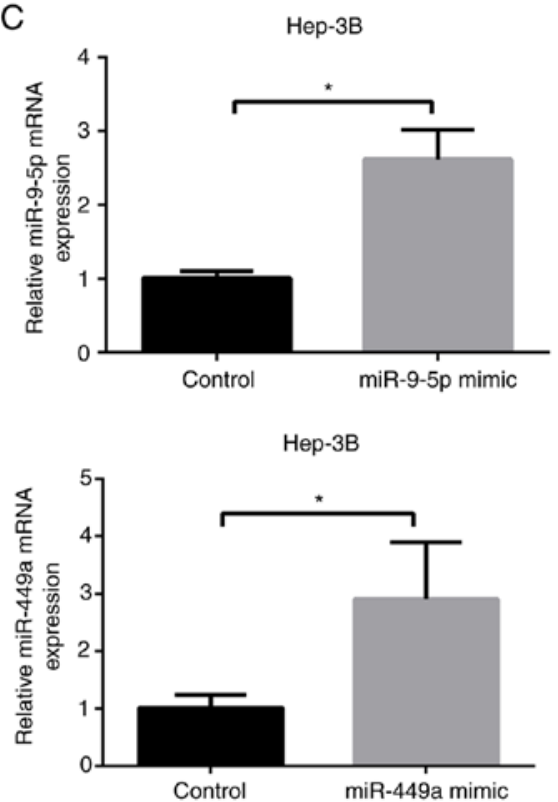

B
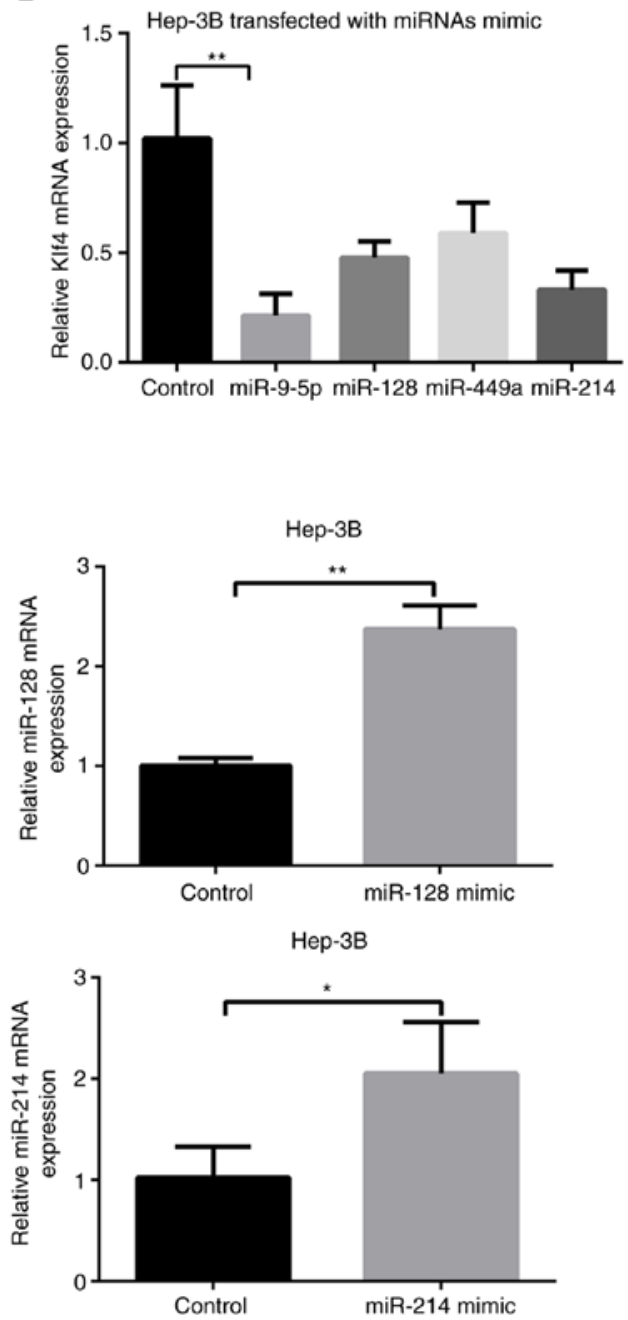

Figure 1. miRNAs that potentially downregulate Klf4 expression in HCC. (A) Crossed interaction of miRNAs, according to prediction databases to predict the miRNAs that bind to the 3'-untranslated region of Klf4. (B) The candidate miRNA mimics were transfected into Hep-3B cells, and the expression level of Klf4 was measured by using RT-qPCR. (C) The transfection efficiency of the candidate miRNAs' mimics was measured using RT-qPCR analysis in Hep-3B cells. ${ }^{*} \mathrm{P}<0.05 ;{ }^{* *} \mathrm{P}<0.01$. miRNA or miR, microRNA; HCC, hepatocellular carcinoma; Klf4, Krüppel-like factor 4; RT-qPCR, reverse transcription-quantitative polymerase chain reaction analysis.

and plasmids were separately cloned into luciferase reporter vector, as presented in Fig. 3F. The luciferase reporter assay revealed that the effect of miR-9-5p inhibition was abrogated upon transfection with the mutation type. These results indicated that miR-9-5p regulated the expression of Klf4 through a direct association with the Klf4 3'-UTR.

miR-9-5p affects cell proliferation and apoptosis, activating an AKT-associated pathway via downregulation of Klf4. Transfected cells were seeded to examine their cell proliferative abilities according to CCK8 assay on days 1-5 following transfection. Transfection efficiency of miR-9-5p mimic or inhibitor, or siKlf4/Klf4 was verified by RT-qPCR and western blot analysis (Fig. 4A). The results demonstrated that miR-9-5p mimic significantly promoted proliferation compared with the control, and the effect was reversed by overexpression of Klf4 in the miR-9-5p mimic-treated HCC cells. The results also revealed that miR-9-5p inhibitor inhibited the proliferation of HCC cells, and this effect was circumvented by the addition of siKlf4 to miR-9-5p inhibitor expressing HCC cells (Fig. 4B).
The effects of miR-9-5p and Klf4 on cell apoptosis were further explored using the annexin V/PI flow cytometric method. The quantitative apoptosis assay demonstrated that miR-9-5p mimic inhibited apoptosis via Klf4 in SK-Hep-1 cells, whereas miR-9-5p inhibitor accelerated cell apoptosis in HCC-LM3 cells (Fig. 4C). To understand the mechanisms underpinning how the miR-9-5p/Klf4 axis functions, the expression levels of total AKT, p-AKT, mTOR and p-mTOR protein were measured by western blot analysis. The results revealed that the miR-9-5p/Klf4 axis activated the process of AKT and mTOR phosphorylation. Subsequently, the expression levels of the apoptosis-associated proteins Bcl-2 and Bax, were examined. The results disclosed that the miR-9-5p/Klf4 axis increased the level of the anti-apoptotic protein Bcl-2 and decreased that of the apoptotic protein, Bax (Fig. 4D). On the basis of these results, It was possible to conclude that the miR-9-5p/Klf4 axis may activate the AKT/mTOR-associated pathway. To substantiate the hypothesis that the AKT/mTOR-associated pathway mediates apoptosis of the activated miR-9-5p/Klf4 axis in HCC cells, 
A

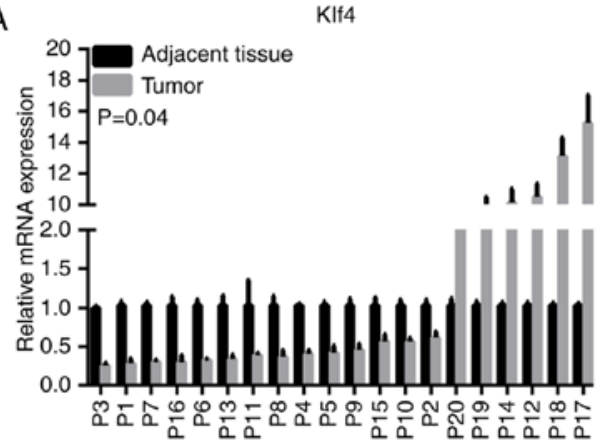

B

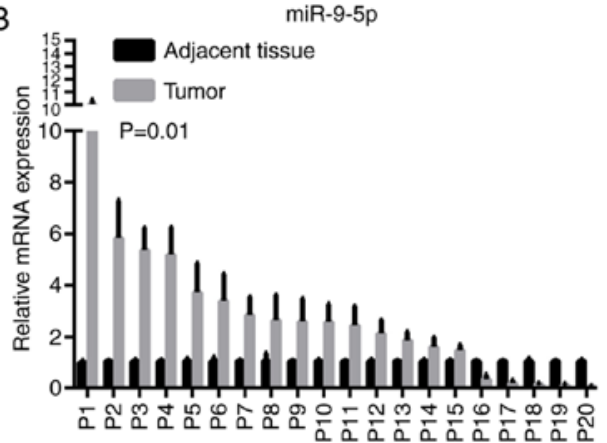

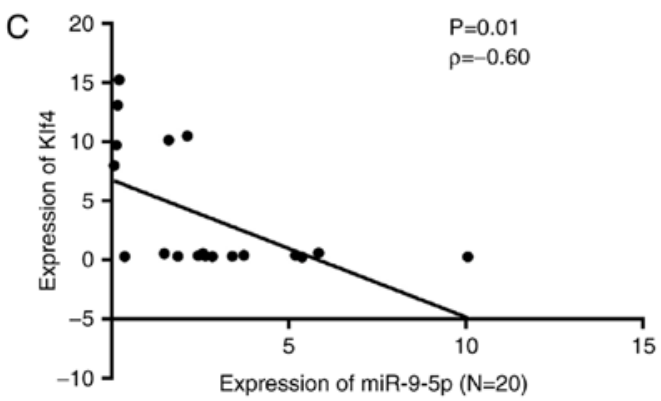
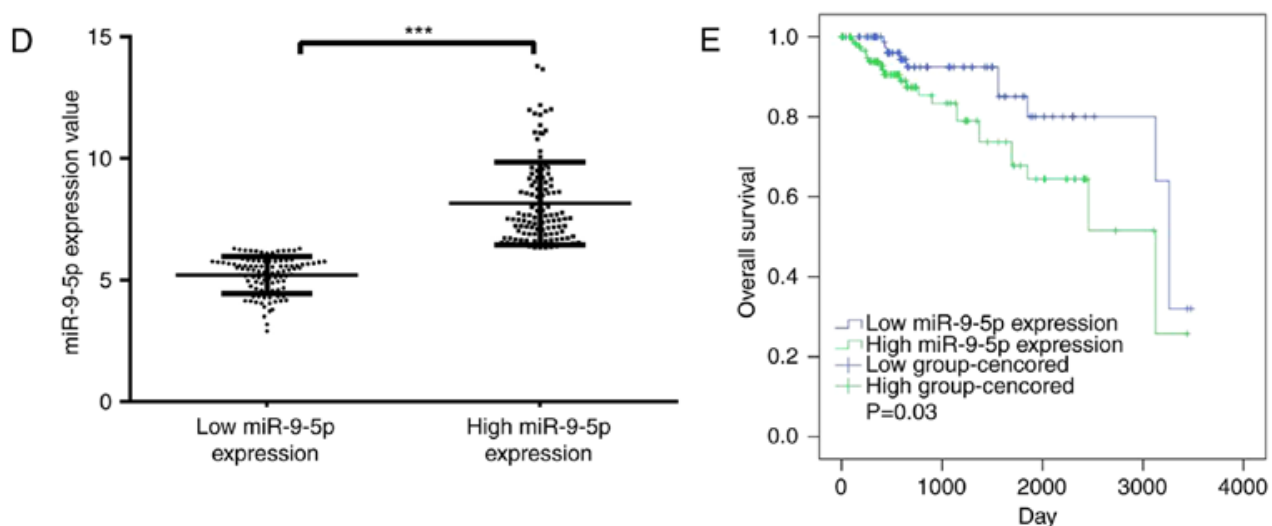

Figure 2. miR-9-5p overexpression in clinical samples is associated with low expression of Klf4 and a poor prognosis of HCC. Reverse transcription-quantitative polymerase chain reaction analysis of (A) Klf4 and (B) miR-9-5p in clinical tissue. (C) Inverse correlation between miR-9-5p and Klf4 in patients, as determined by Spearman's correlation. (D) miR-9-5p expression levels between the high and low expression groups, separated by the median value. A statistically significant difference existed between two groups. ${ }^{* * *} \mathrm{P}<0.001$. (E) Kaplan-Meier analysis of patients with HCC based on different expression levels of miR-9-5p obtained from The Cancer Genome Atlas HCC database (P=0.027). miR, microRNA; HCC, hepatocellular carcinoma; Klf4, Krüppel-like factor 4.

whether the cell proliferative capability is reinforced when AKT is inhibited was investigated. The results obtained revealed that $\mathrm{MK}-2206,2 \mathrm{HCl}$, an $\mathrm{AKT}$ inhibitor, notably reduced the proliferation-promoting apoptosis effect of activated miR-9-5p/Klf4 axis HCC cells (Fig. 4E and F).

miR-9-5p enhances the HCC migration ability of HCC cells via downregulating Klf4. To evaluate the effect of miR-9-5p downregulating Klf4 on cell migration, miR-9-5p mimic and inhibitor, Klf4, and siKlf4 were respectively transfected into SK-Hep-1 and HCC-LM3 cells. Cell migration rates were increased in the miR-9-5p mimic group compared with the control, and they were also increased in the miR-9-5p mimic-Klf4 group compared with the Klf4 group. Furthermore, the migration rates were decreased in the miR-9-5p inhibitor group compared with the control; likewise, they were decreased in the miR-9-5p inhibitor-siKlf4 group compared with the siKlf4 group. In addition, the Transwell migration assay gave rise to similar results as those of the wound healing assay (Fig. 5A and B). Taken together, these results indicated that miR-9-5p promoted the migrational capabilities of the HCC cells by decreasing Klf4 expression.

\section{Discussion}

A characteristic of HCC cells is that they readily take up therapeutic agents, such as antisense oligonucleotides, a property that may be exploited in the search for functional noncoding RNAs (ncRNAs) as potential targets for HCC treatment $(36,37)$. With numerous studies illustrating the signaling mechanisms of ncRNAs (38), researchers' attention has been drawn towards investigating the effects of ectopic miRNA expression on the proliferation and apoptosis of HCC cells. A HCC study (39) have revealed that miRNAs regulate the expression of various oncogenes and tumor suppressor genes, contributing to the modulation of diverse biological processes, including proliferation, 
Table I. Characteristics of 20 hepatocellular carcinoma cases.

\begin{tabular}{|c|c|c|c|c|c|c|c|}
\hline \multirow[b]{2}{*}{ Characteristic } & \multirow[b]{2}{*}{ Patients } & \multicolumn{3}{|c|}{ miR-9-5p } & \multicolumn{3}{|c|}{ Klf4 } \\
\hline & & High & Low & P-value & High & Low & P-value \\
\hline Age, years & & & & 0.423 & & & 0.423 \\
\hline$<60$ & $7(35)$ & $4(20)$ & $3(15)$ & & $4(20)$ & $3(15)$ & \\
\hline$\geq 60$ & $13(65)$ & $4(20)$ & $9(45)$ & & $5(25)$ & $8(40)$ & \\
\hline Sex & & & & 0.081 & & & 0.888 \\
\hline Male & $13(65)$ & $4(20)$ & $9(45)$ & & $6(30)$ & $7(35)$ & \\
\hline Female & $7(35)$ & $5(25)$ & $2(10)$ & & $3(15)$ & $4(20)$ & \\
\hline Tumor size, cm & & & & 0.078 & & & 0.064 \\
\hline$\leq 5$ & $9(45)$ & $6(30)$ & $3(15)$ & & $2(10)$ & $7(35)$ & \\
\hline$>5$ & $11(55)$ & $3(15)$ & $8(40)$ & & $7(35)$ & $4(20)$ & \\
\hline Stage & & & & 0.436 & & & 0.436 \\
\hline I, II & $15(75)$ & $6(30)$ & $9(45)$ & & $6(30)$ & $9(45)$ & \\
\hline III & $5(25)$ & $3(15)$ & $2(10)$ & & $3(15)$ & $2(10)$ & \\
\hline MVI & & & & 0.582 & & & 0.714 \\
\hline 0 & $12(60)$ & $6(30)$ & $6(30)$ & & $5(25)$ & $7(35)$ & \\
\hline$\geq 1$ & $8(40)$ & $3(15)$ & $5(25)$ & & $4(20)$ & $4(20)$ & \\
\hline
\end{tabular}

Data are provided as n (\%). miR, microRNA; Klf4, Krüppel-like factor 4; MVI, microvascular invasion.

Table II. Correlation of miR-9-5p expression with clinicopathological features of hepatocellular carcinoma in The Cancer Genome Atlas database.

\begin{tabular}{|c|c|c|c|c|c|c|}
\hline \multirow[b]{2}{*}{ Characteristic } & \multirow[b]{2}{*}{ Patients, $\mathrm{n}$} & \multicolumn{2}{|c|}{$\begin{array}{l}\text { High miR-9-5p } \\
\text { expression }\end{array}$} & \multicolumn{2}{|c|}{$\begin{array}{c}\text { Low miR-9-5p } \\
\text { expression }\end{array}$} & \multirow[b]{2}{*}{ P-value } \\
\hline & & $\mathrm{n}$ & $\%$ & $\mathrm{n}$ & $\%$ & \\
\hline Age, years & & & & & & 0.328 \\
\hline$<60$ & 98 & 50 & 51.0 & 48 & 49.0 & \\
\hline$\geq 60$ & 126 & 56 & 44.4 & 70 & 55.6 & \\
\hline Sex & & & & & & 0.290 \\
\hline Male & 155 & 77 & 49.7 & 78 & 50.3 & \\
\hline Female & 69 & 29 & 42.0 & 40 & 58.0 & \\
\hline $\mathrm{AFP}, \mu \mathrm{g} / \mathrm{l}$ & & & & & & 0.122 \\
\hline$<400$ & 88 & 36 & 40.9 & 52 & 59.1 & \\
\hline$\geq 400$ & 136 & 70 & 51.5 & 66 & 48.5 & \\
\hline Pathological stage & & & & & & 0.263 \\
\hline I/ II & 220 & 103 & 46.8 & 117 & 53.2 & \\
\hline III/IV & 4 & 3 & 75.0 & 1 & 25.0 & \\
\hline Vascular invasion & & & & & & 0.718 \\
\hline Yes & 66 & 30 & 45.5 & 36 & 54.5 & \\
\hline No & 158 & 76 & 48.1 & 82 & 51.9 & \\
\hline
\end{tabular}

AFP, $\alpha$ fetoprotein.

apoptosis, epithelial-to-mesenchymal transition and metastasis. An unusual feature of miRNAs is their ability to bind to various different target genes, and to inhibit the process of translation (39-41). For example, an induced increase in the level of miR-188-5p markedly inhibited fibroblast growth factor 5 (FGF5), whereas the restoration of FGF5 expression 
Table III. Survival rate of low and high miR-9-5p expression groups.

\begin{tabular}{lccr}
\hline miR-9-5p expression & 1-year survival & 3-year survival & 5-year survival \\
\hline Low & 98.0 & 87.9 & 80.2 \\
High & 95.1 & 86.8 & 71.8 \\
\hline
\end{tabular}

Data are presented as \% values of the total cohort. miR, microRNA.
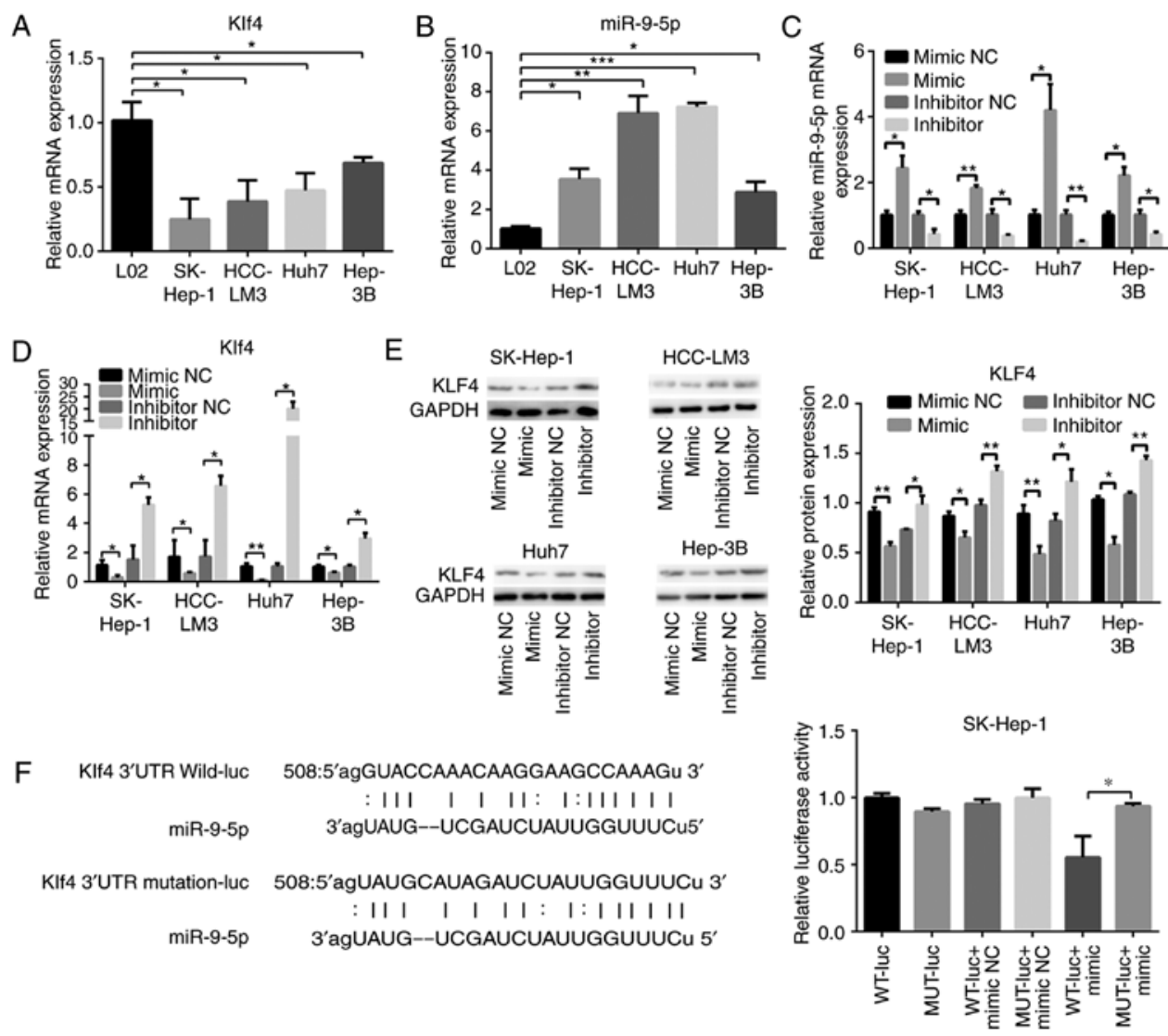

Figure 3. miR-9-5p regulates the transcription factor Klf4 in HCC cells. RT-qPCR analysis of (A) Klf4 and (B) miR-9-5p in L02 and HCC cells. (C and D) RT-qPCR and (E) western blot analysis of mRNA and protein expression levels, respectively, of Klf4 and miR-9-5p at $48 \mathrm{~h}$ following transfection with $100 \mathrm{nM}$ miR-9-5p mimic or $100 \mathrm{nM}$ inhibitor, and their control groups in HCC cells. (F) The binding site of miR-9-5p was predicted in the Klf4 3'-UTR. Subsequently, the luciferase reporters of the WT or MUT miR-9-5p targeting Klf4 3'-UTR sites was constructed. Luciferase activity was measured $48 \mathrm{~h}$ following transfection of miR-9-5p mimic or negative control, together with WT or MUT Klf4 3'-UTR. ${ }^{*} \mathrm{P}<0.05 ;{ }^{* *} \mathrm{P}<0.01$; ${ }^{* * *} \mathrm{P}<0.001$. RT-qPCR, reverse transcription-quantitative polymerase chain reaction; miR, microRNA; HCC, hepatocellular carcinoma; mimic NC, mimic negative control; inhibitor NC, inhibitor negative control; Klf4, Krüppel-like factor 4; 3'-UTR, 3'-untranslated region; WT, wild-type; MUT, mutation-type.

reversed the inhibitory effects on HCC progression (42). miR-130b overexpression reduced the expression of tumor protein 53 -induced nuclear protein 1 , which promoted the growth and self-renewal of $\mathrm{CD} 133^{+}$liver tumor-initiating cells (43).

miRNA prediction websites have indicated that miR-9-5p is an upstream gene of Klf4. Previous studies have reported that miR-9-5p is ectopically regulated in various types of cancers. miR-9-5p levels are higher in metastatic tumors compared with non-metastatic tumors and these were demonstrated to be associated with poor prognosis of rhabdomyosarcomas (44). The homeotic gene miR-9 inhibited ovarian cancer cell growth via nuclear factor- $\kappa \beta 1$ (45). Inhibition of the expression of the circular RNA, circMTO1, in HCC directly repressed p21, the target of oncogenic miR-9, and this resulted in the promotion of cell proliferation and invasion (46).

Klf4 is a transcription factor that is involved in the pathogenesis and metastasis of digestive tumors (47) and is downregulated in HCC (23). Klf4 functions as a tumor suppressor gene, and a decrease in Klf4 expression levels is strongly associated with poor survival rates in patients with HCC (23). In our previous study (20), it was demonstrated that the expression level of miR-135a-5p was upregulated in clinical HCC tissues, and this was inversely correlated with the expression of Klf4. miR-135a-5p promoted proliferation and metastasis in HCC cells by directly targeting Klf4 in vitro and in vivo. miRNAs have been confirmed as potential therapeutic targets for HCC; however, further studies that explore the 

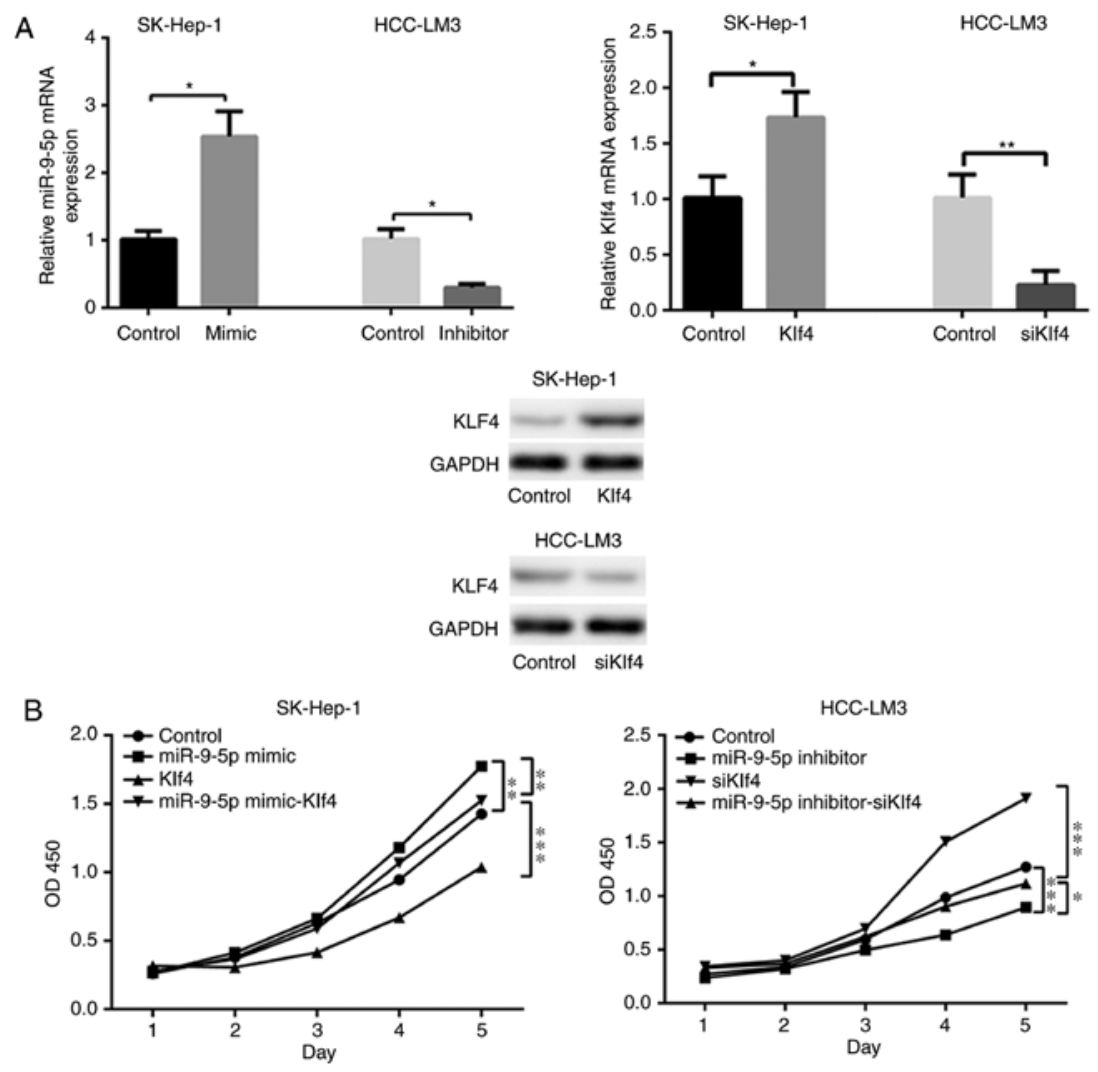

C
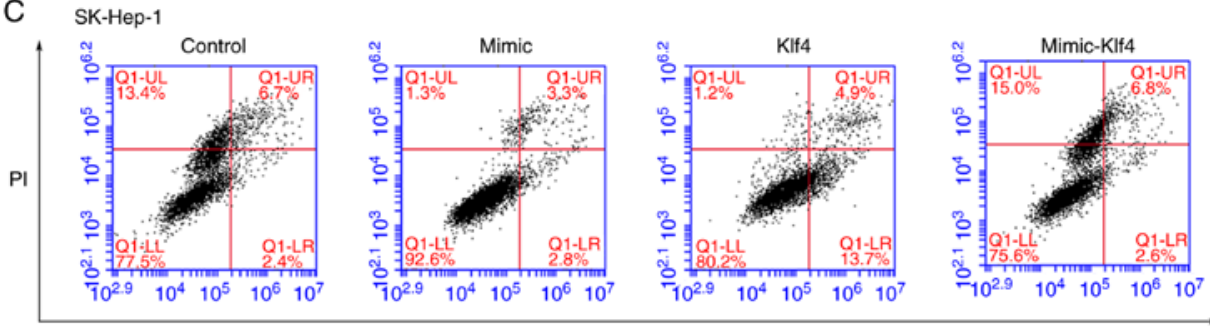

Annexin V-FITC
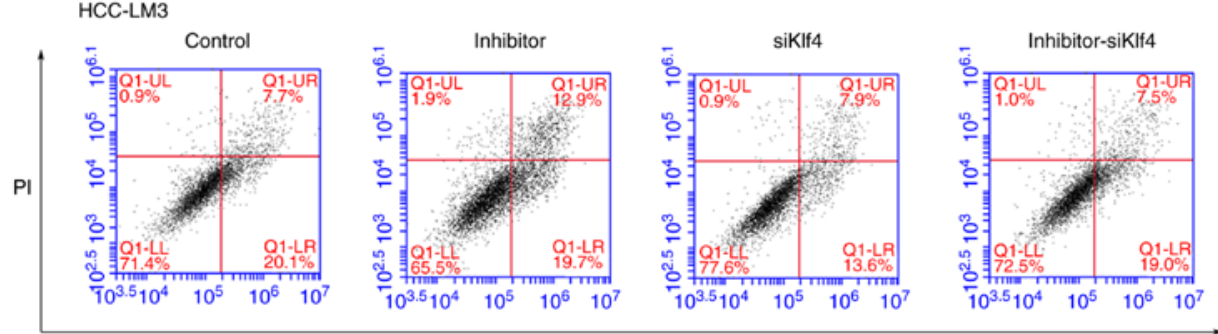

Annexin V-FITC
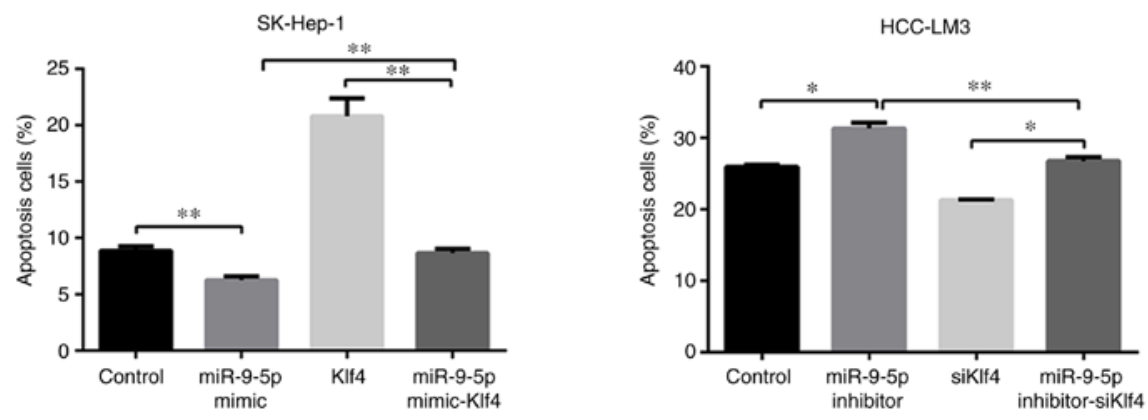

Figure 4. miR-9-5p/Klf4 axis enhances HCC cell proliferation via an AKT/mTOR-associated pathway. (A) The transfection efficiency of miR-9-5p mimic or inhibitor, or siKlf4/Klf4 was measured using reverse transcription-quantitative polymerase chain reaction and western blot analysis. (B) Cell proliferation viability was determined by cell counting kit- 8 assay. A total number of 2,000 transfected cells dissolved in $100 \mu 110 \%$ fetal bovine serum were seeded into 96-well plates on days 1-5, and the absorbance was measured at $450 \mathrm{~nm}$ every $24 \mathrm{~h}$ to obtain a cell growth curve. (C) Flow cytometric analysis of SK-Hep-1 and HCC-LM3 cells treated with miR-9-5p mimic or inhibitor, or siKlf4/Klf4 for $48 \mathrm{~h}$. Representative data are featured, presenting the population of living cells (Annexin V-FITC-/PI-) in the left lower quadrant, early apoptotic cells (Annexin V-FITC+/PI-) in right lower quadrant, late apoptotic cells (Annexin V-FITC +/PI+) in the right upper quadrant and necrotic cells (Annexin V-FITC -/PI+) in the left upper quadrant. 
D

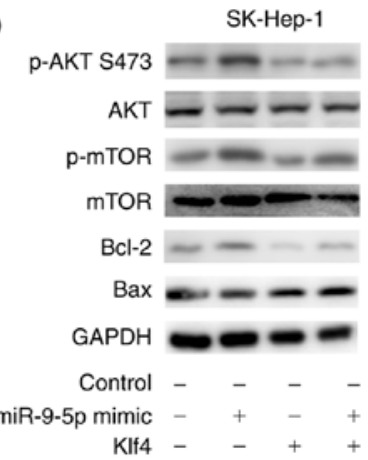

E SK-Hep-1
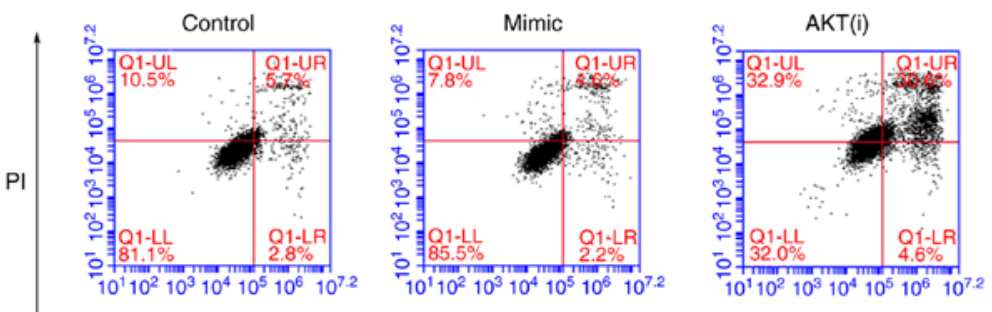

HCC-LM3

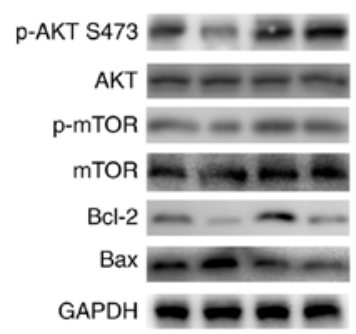

Control - - - -

miR-9-5p inhibitor -++-+
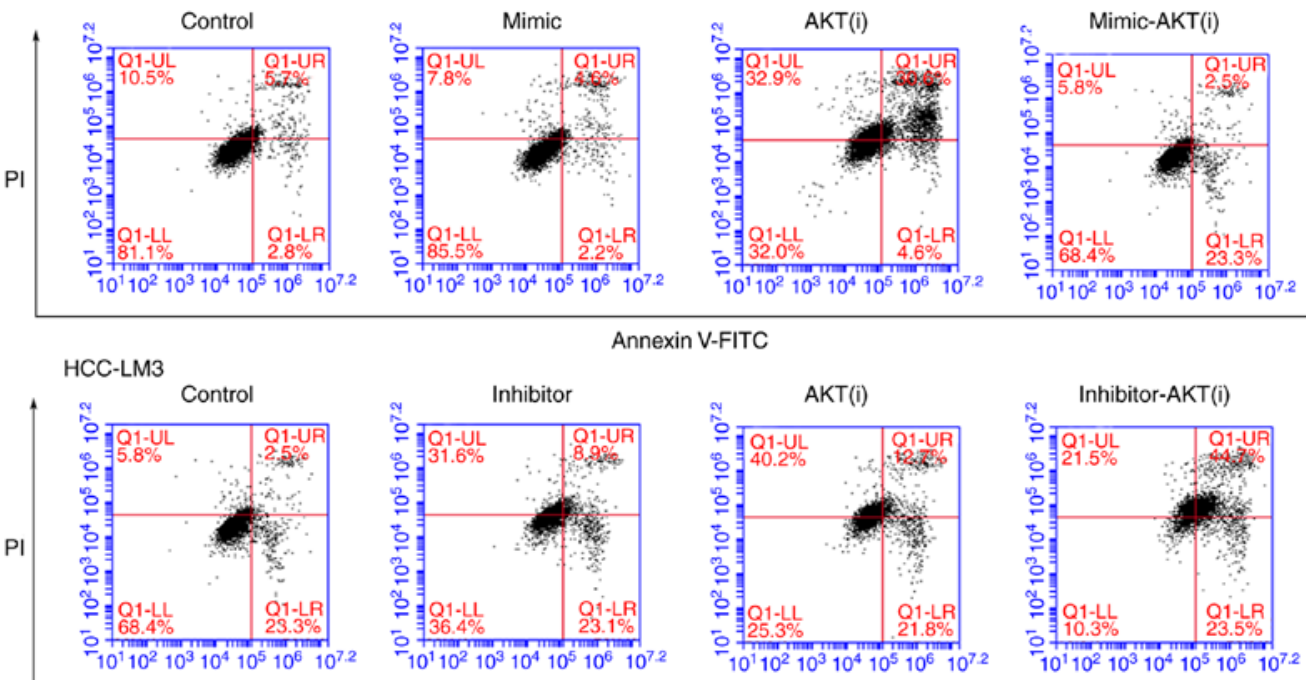

Annexin V-FITC

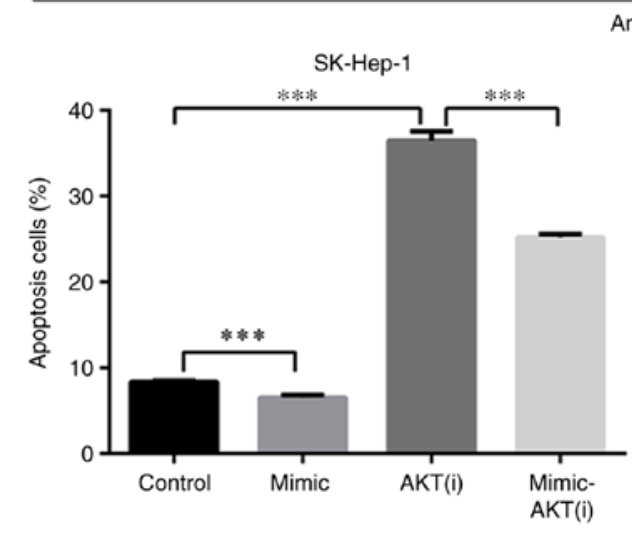

Annexin V-FITC

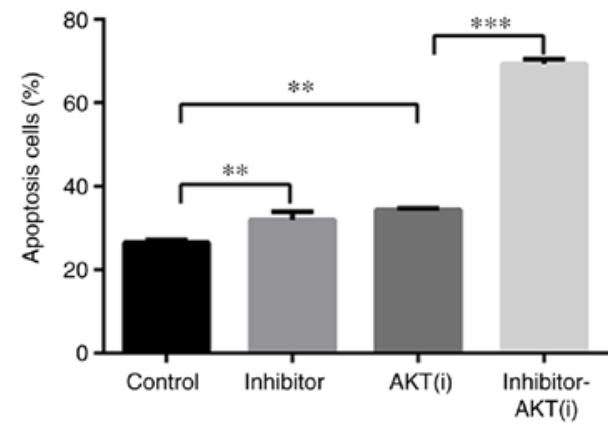

F

SK-Hep-1
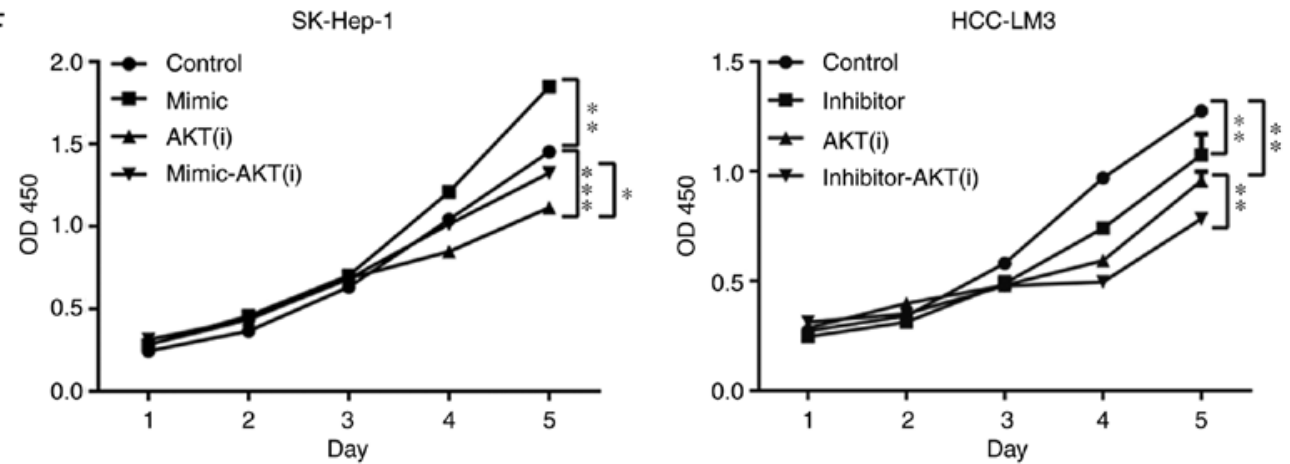

Figure 4. Continued. (D) Levels of AKT, p-AKT S473, mTOR, p-mTOR, Bcl-2 and Bax were examined by western blotting in SK-Hep-1 and HCC-LM3 cells transfected with miR-9-5p mimic/inhibitor or Klf4/siKlf4. (E) Flow cytometric analysis of SK-Hep-1 and HCC-LM3 cells treated with miR-9-5p mimic/inhibitor together with AKTi (10 $\mu$ l, MK-2206, $2 \mathrm{HCl}$; dissolved in DMSO) for $48 \mathrm{~h}$. (F) Cell proliferation analysis of SK-Hep-1 and HCC-LM3 cells treated with miR-9-5p mimic/inhibitor with AKT inhibitor (10 $\mu 1$, MK-2206, $2 \mathrm{HCl}$; dissolved in DMSO) for $48 \mathrm{~h} .{ }^{*} \mathrm{P}<0.05 ;{ }^{* *} \mathrm{P}<0.01 ;{ }^{* * * *} \mathrm{P}<0.001$. miR, microRNA; p, phosphorylated; AKT, protein kinase B; mTOR, mechanistic target of rapamycin; DMSO, dimethyl sulfoxide; HCC, hepatocellular carcinoma; Klf4, Krüppel-like factor 4; siKlf4, small interfering RNA against Klf4; PI, propidium iodide; FITC, fluorescein isothiocyanate; Bcl-2, B cell lymphoma-2; Bax, Bcl-2-associated $\mathrm{X}$ protein; OD, optical density; AKTi, AKT inhibitor. 

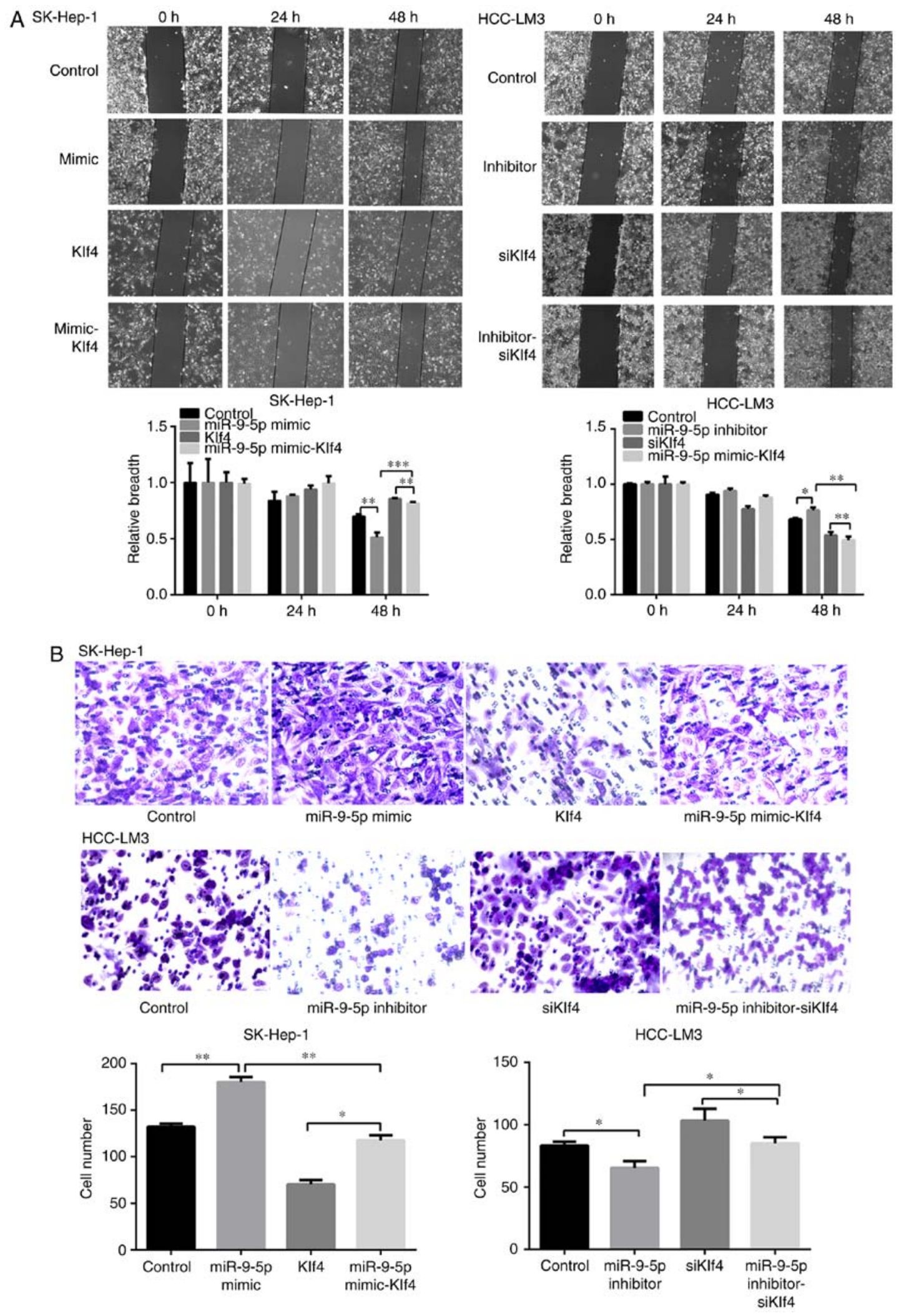

Figure 5. miR-9-5p enhances HCC cell migration by Klf4. (A) Wound healing assay of SK-Hep-1 and HCC-LM3 cells treated with miR-9-5p mimic/inhibitor or siKlf4/Klf4 for $48 \mathrm{~h}$. Images were taken in randomly selected fields at a higher magnification (x40). (B) Cell migration assay in SK-Hep-1 and HCC-LM3 cells transfected with $100 \mathrm{nM}$ miR-9-5p mimic/inhibitor or $2 \mu \mathrm{g}$ Klf4/siKlf4. Images were acquired at a higher magnification (x40) at the fixed location of the panel. Numbers of migratory cells number were counted and are presented in the bar graph. Representative images are presented. ${ }^{*} \mathrm{P}<0.05 ;{ }^{* * *} \mathrm{P}<0.01 ;{ }^{* * * *} \mathrm{P}<0.001$ vs. control. miR, microRNA; HCC, hepatocellular carcinoma; Klf4, Krüppel-like factor 4; siKlf4, small interfering RNA against Klf4.

mechanisms underpinning the involvement of on miRNAs in HCC are required. The results of the present study have confirmed that miR-9-5p expression was inversely associated with Klf4 expression in HCC clinical samples. Furthermore, a poor prognosis of $\mathrm{HCC}$ was significantly correlated with overexpression of miR-9-5p according to the TCGA HCC 
database. However, no comparatively thorough studies have been performed concerning the role of miR-9-5p as a regulator of Klf4.

Further experiments performed in the present study confirmed that Klf4 was directly inhibited by miR-9-5p in the HCC cells. These findings further supported that miR-9-5p increased cell proliferation, and inhibited apoptosis, by downregulating Klf4. AKT-associated signaling pathways fulfill important roles in HCC (48). miR-7 functions as a tumor suppressor, and regulates the AKT pathway (49). Klf4 was found to be associated with phosphorylated sites of AKT, and had a role in AKT-mediated phosphorylation (17). Via the suppression of Klf4 and activating AKT/mTOR signaling, miR-9-5p accelerated the progression of HCC. Apoptosis is perhaps governed by the Bcl-2 family of proteins, which act as molecular 'sentinels', determining the mitochondrial response to apoptosis stimuli. Dysregulation of $\mathrm{Bcl}-2 / \mathrm{Bax}$ facilitates tumorigenesis and tumor progression (50). The results of the present study suggested that the miR-9-5p/Klf4 axis had an inhibitory effect on the apoptotic protein, Bax, and served to activate the anti-apoptotic protein, $\mathrm{Bcl}-2$, by targeting the AKT pathway.

In conclusion, the findings of the present study have demonstrated that the high expression level of miR-9-5p in HCC are associated with poor prognosis of disease, and miR-9-5p directly targets Klf4, which has been widely demonstrated as a suppressor gene in HCC. The miR-9-5p/Klf4 axis promoted the proliferation, and accelerated the migration, of HCC cells, and inhibited apoptosis by activating the AKT/mTOR pathway. it is to hoped that studying the miR-9-5p/Klf4 regulation mechanism will stimulate a greater level of interest in prospective studies, and these will lead to the discovery of novel and effective therapeutic targets for HCC treatment. The present study has contributed to this process by uncovering the role of miR-9-5p as a prognostic marker and potential therapeutic target.

\section{Acknowledgements}

Not applicable.

\section{Funding}

The present study was supported by grants from the National Natural Science Foundation of China (grant nos. 81272714 and 81572310).

\section{Availability of data and materials}

The datasets used and/or analyzed during the current study are available from the corresponding author on reasonable request.

\section{Authors' contributions}

$\mathrm{XD}$ and $\mathrm{FW}$ conducted the experiments and wrote the manuscript. YX, ZL and WS performed the experiments. XD, NY and QL analyzed the data. All authors read and approved the final version of the manuscript.

\section{Ethics approval and consent to participate}

All experimental protocols were approved by the Ethics Committee of Eastern Hepatobiliary Surgery Hospital, The Second Military Medical University. Informed consent was obtained from all patients.

\section{Patient consent for publication}

Not applicable.

\section{Competing interests}

The authors declare that they have no competing interests.

\section{References}

1. Siegel RL, Miller KD and Jemal A: Cancer statistics, 2018. CA Cancer J Clin 68: 7-30, 2018.

2. Guo H, Wu T, Lu Q, Li M, Guo JY, Shen Y, Wu Z, Nan KJ, Lv Y and Zhang XF: Surgical resection improves long-term survival of patients with hepatocellular carcinoma across different Barcelona clinic liver cancer stages. Cancer Manag Res 10: 361-369, 2018.

3. Li T, Xie J, Shen C, Cheng D, Shi Y, Wu Z, Deng X, Chen H, Shen B, Peng C, et al: Upregulation of long noncoding RNA ZEB1-AS1 promotes tumor metastasis and predicts poor prognosis in hepatocellular carcinoma. Oncogene 35: 1575-1584, 2016.

4. Llovet JM, Ricci S, Mazzaferro V, Hilgard P, Gane E, Blanc JF, de Oliveira AC, Santoro A, Raoul JL, Forner A, et al: Sorafenib in advanced hepatocellular carcinoma. N Engl J Med 359: 378-390, 2008.

5. Kudo M: Systemic therapy for hepatocellular carcinoma: Latest advances. Cancers (Basel) 10: pii: E412, 2018.

6. Augello G, Emma MR, Cusimano A, Azzolina A, Mongiovi S, Puleio R, Cassata G, Gulino A, Belmonte B, Gramignoli R, et al: Targeting HSP90 with the small molecule inhibitor AUY922 (luminespib) as a treatment strategy against hepatocellular carcinoma. Int J Cancer Nov 29, 2018 (Epub ahead of print).

7. Harris WP, Wong KM, Saha S, Dika IE and Abou-Alfa GK: Biomarker-driven and molecular targeted therapies for hepatobiliary cancers. Semin Oncol 45: 116-123, 2018.

8. Zhang Q, Wei L, Yang H, Yang W, Yang Q, Zhang Z, Wu K, $\mathrm{Wu} \mathrm{J}$ and $\mathrm{Wu} \mathrm{J}$ : Bromodomain containing protein represses the Ras/Raf/MEK/ERK pathway to attenuate human hepatoma cell proliferation during HCV infection. Cancer Lett 371: 107-116, 2016.

9. Chai S, Ng KY, Tong M, Lau EY, Lee TK, Chan KW, Yuan YF, Cheung TT, Cheung ST, Wang XQ, et al: Octamer 4/microRNA-1246 signaling axis drives $\mathrm{Wnt} / \beta$-catenin activation in liver cancer stem cells. Hepatology 64: 2062-2076, 2016.

10. Ou DL, Lee BS, Lin LI, Liou JY, Liao SC, Hsu C and Cheng AL: Vertical blockade of the IGFR- PI3K/Akt/mTOR pathway for the treatment of hepatocellular carcinoma: The role of survivin. Mol Cancer 13: 2, 2014.

11. Vivanco I and CL S: The phosphatidylinositol 3-Kinase AKT pathway in human cancer. Nat Rev Cancer 7: 489-501, 2002.

12. Presnell JS, Schnitzler CE and Browne WE: KLF/SP Transcription factor family evolution: Expansion, diversification, and innovation in eukaryotes. Genome Biol Evol 7: 2289-2309, 2015.

13. Hu JH, Navas P, Cao H, Stamatoyannopoulos G and Song CZ: Systematic RNAi studies on the role of Sp/KLF factors in globin gene expression and erythroid differentiation. J Mol Biol 366: 1064-1073, 2007.

14. Carrano AC, Dillin A and Hunter T: A Krüppel-like factor downstream of the E3 ligase WWP-1 mediates dietary-restriction-induced longevity in Caenorhabditis elegans. Nat Commun 5: 3772, 2014.

15. Kim CK, He P, Bialkowska AB and Yang VW: SP and KLF transcription factors in digestive physiology and diseases. Gastroenterology 152: 1845-1875, 2017. 
16. Chen HY, Lin YM, Chung HC, Lang YD, Lin CJ, Huang J, Wang WC, Lin FM, Chen Z, Huang HD, et al: miR-103/107 promote metastasis of colorectal cancer by targeting the metastasis suppressors DAPK and KLF4. Cancer Res 72: 3631-3641, 2012.

17. Malak PN, Dannenmann B, Hirth A, Rothfuss OC and Schulze-Osthoff K: Novel AKT phosphorylation sites identified in the pluripotency factors OCT4, SOX2 and KLF4. Cell Cycle 14: 3748-3754, 2015.

18. Hsu YY, Liu CM, Tsai HH, Jong YJ, Chen IJ and Lo YC: KMUP-1 attenuates serum deprivation-induced neurotoxicity in SH-SY5Y cells: Roles of PKG, PI3K/Akt and Bcl-2/Bax pathways. Toxicology 268: 46-54, 2010.

19. Muir KR, Lima MJ, Docherty HM, McGowan NW, Forbes S, Heremans Y, Forbes SJ, Heimberg H, Casey J and Docherty K: Krüppel-Like factor 4 overexpression initiates a mesenchymal-to-epithelial transition and redifferentiation of human pancreatic cells following expansion in long term adherent culture. PLoS One 10: e0140352, 2015.

20. Sun H, Peng Z, Tang H, Xie D, Jia Z, Zhong L, Zhao S, Ma Z, Gao Y, Zeng L, et al: Loss of KLF4 and consequential downregulation of Smad7 exacerbate oncogenic TGF- $\beta$ signaling in and promote progression of hepatocellular carcinoma. Oncogene 36: 2957-2968, 2017.

21. Chang YL, Zhou PJ, Wei L, Li W, Ji Z, Fang YX and Gao WQ: MicroRNA-7 inhibits the stemness of prostate cancer stem-like cells and tumorigenesis by repressing KLF4/PI3K/Akt/p21 pathway. Oncotarget 6: 24017-24031, 2015

22. Li Z, Zhao J, Li Q, Yang W, Song Q, Li W and Liu J: KLF4 promotes hydrogen-peroxide-induced apoptosis of chronic myeloid leukemia cells involving the bcl-2/bax pathway. Cell Stress Chaperones 15: 905-912, 2010.

23. Li Q, Gao Y, Jia Z, Mishra L, Guo K, Li Z, Le X, Wei D, Huang S and Xie K: Dysregulated Krüppel-like factor 4 and vitamin D receptor signaling contribute to progression of hepatocellular carcinoma. Gastroenterology 143: 799-810.e2, 2012.

24. Bartel DP: MicroRNAs: Genomics, biogenesis, mechanism, and function. Cell 116: 281-297, 2004.

25. Wang LQ, Zhang Y, Yan H, Liu KJ and Zhang S: MicroRNA-373 functions as an oncogene and targets YOD1 gene in cervical cancer. Biochem Biophys Res Commun 459: 515-520, 2015.

26. Yuan J, Ji H, Xiao F, Lin Z, Zhao X, Wang Z, Zhao J and Lu J: MicroRNA-340 inhibits the proliferation and invasion of hepatocellular carcinoma cells by targeting JAK1. Biochem Biophys Res Commun 483: 578-584, 2017.

27. Yao S, Tian C, Ding Y, Ye Q, Gao Y, Yang N and Li Q Down-regulation of Krüppel-like factor-4 by microRNA-135a-5p promotes proliferation and metastasis in hepatocellular carcinoma by transforming growth factor- $\beta 1$. Oncotarget 7 : 42566-42578, 2016

28. Mirihana Arachchilage G, Kharel P, Reid J and Basu S: Targeting of G-quadruplex harboring Pre-miRNA 92b by LNA rescues PTEN expression in NSCL cancer cells. ACS Chem Biol 13: 909-914, 2018.

29. Varnholt H, Drebber U, Schulze F, Wedemeyer I, Schirmacher P, Dienes HP and Odenthal M: MicroRNA gene expression profile of hepatitis C virus-associated hepatocellular carcinoma. Hepatology 47: 1223-1232, 2008.

30. Amin MB, Greene FL, Edge SB, Compton CC, Gershenwald JE, Brookland RK, Meyer L, Gress DM, Byrd DR and Winchester DP: The eighth edition AJCC cancer staging manual: Continuing to build a bridge from a population-based to a more 'personalized' approach to cancer staging. CA Cancer J Clin 67: 93-99, 2017.

31. Kamarajah SK, Frankel TL, Sonnenday C, Cho CS and Nathan H: Critical evaluation of the American joint commission on cancer (AJCC) 8th edition staging system for patients with hepatocellular carcinoma (HCC): A surveillance, epidemiology, end results (SEER) analysis. J Surg Oncol 117: 644-650, 2018.

32. Livak KJ and Schmittgen TD: Analysis of relative gene expression data using real-time quantitative PCR and the 2(-Delta Delta C(T)) method. Methods 25: 402-408, 2001.

33. Zawada AM, Rogacev KS, Muller S, Rotter B, Winter P, Fliser D and Heine GH: Massive analysis of cDNA Ends (MACE) and miRNA expression profiling identifies proatherogenic pathways in chronic kidney disease. Epigenetics 9: 161-172, 2014.
34. Wang GC, He QY, Tong DK, Wang CF, Liu K, Ding C, Ji F and Zhang H: MiR-367 negatively regulates apoptosis induced by adriamycin in osteosarcoma cells by targeting KLF4. J Bone Oncol 5: 51-56, 2016.

35. Guo Y, An R, Zhao R, Sun Y, Liu M and Tian L: miR-375 exhibits a more effective tumor-suppressor function in laryngeal squamous carcinoma cells by regulating KLF4 expression compared with simple co-transfection of miR-375 and miR-206. Oncol Rep 36: 952-960, 2016.

36. Braconi $\mathrm{C}$ and Patel T: Non-coding RNAs as therapeutic targets in hepatocellular cancer. Curr Cancer Drug Targets 12: 1073-1080, 2012.

37. Zimmermann TS, Lee AC, Akinc A, Bramlage B, Bumcrot D, Fedoruk MN, Harborth J, Heyes JA, Jeffs LB, John M, et al: RNAi-mediated gene silencing in non-human primates. Nature 441: 111-114, 2006.

38. Klingenberg M, Matsuda A, Diederichs S and Patel T: Non-coding RNA in hepatocellular carcinoma: Mechanisms, biomarkers and therapeutic targets. J Hepatol 67: 603-618, 2017.

39. Hayes CN and Chayama K: MicroRNAs as biomarkers for liver disease and hepatocellular carcinoma. Int J Mol Sci 17: 280, 2016.

40. He S, Zhang DC and Wei C: MicroRNAs as biomarkers for hepatocellular carcinoma diagnosis and prognosis. Clin Res Hepatol Gastroenterol 39: 426-434, 2015.

41. Yang N, Ekanem NR, Sakyi CA and Ray SD: Hepatocellular carcinoma and microRNA: New perspectives on therapeutics and diagnostics. Adv Drug Deliv Rev 81: 62-74, 2015.

42. Fang F, Chang RM, Yu L, Lei X, Xiao S, Yang H and Yang LY: MicroRNA-188-5p suppresses tumor cell proliferation and metastasis by directly targeting FGF5 in hepatocellular carcinoma. J Hepatol 63: 874-885, 2015.

43. Ma S, Tang KH, Chan YP, Lee TK, Kwan PS, Castilho A, Ng I, Man K, Wong N, To KF, et al: miR-130b promotes CD133(+) liver tumor-initiating cell growth and self-renewal via tumor protein 53-induced nuclear protein 1. Cell Stem Cell 7: 694-707, 2010.

44. Missiaglia E, Shepherd CJ, Aladowicz E, Olmos D, Selfe J, Pierron G, Delattre O, Walters Z and Shipley J: MicroRNA and gene co-expression networks characterize biological and clinical behavior of rhabdomyosarcomas. Cancer Lett 385: 251-260, 2017

45. Guo LM, Pu Y, Han Z, Liu T, Li TX, Liu M, Li X and Tang H: MicroRNA-9 inhibits ovarian cancer cell growth through regulation of NF-kappaB1. FEBS J 276: 5537-5546, 2009.

46. Han D, Li J, Wang H, Su X, Hou J, Gu Y, Qian C, Lin Y, Liu X, Huang M, et al: Circular RNA circMTO1 acts as the sponge of microRNA-9 to suppress hepatocellular carcinoma progression. Hepatology 66: 1151-1164, 2017.

47. Tang W, Zhu Y, Gao J, Fu J, Liu C, Liu Y, Song C, Zhu S, Leng Y, Wang G, et al: MicroRNA-29a promotes colorectal cancer metastasis by regulating matrix metalloproteinase 2 and E-cadherin via KLF4. Br J Cancer 110: 450-458, 2014.

48. Calvisi DF, Wang C, Ho C, Ladu S, Lee SA, Mattu S, Destefanis G, Delogu S,Zimmermann A, Ericsson J, et al: Increased lipogenesis, induced by AKT-mTORC1-RPS6 signaling, promotes development of human hepatocellular carcinoma. Gastroenterology 140: 1071-1083, 2011

49. Fang Y, Xue JL, Shen Q, Chen J and Tian L: MicroRNA-7 inhibits tumor growth and metastasis by targeting the phosphoinositide 3-kinase/Akt pathway in hepatocellular carcinoma. Hepatology 55: 1852-1862, 2012.

50. Hata AN, Engelman JA and Faber AC: The BCL2 family: Key mediators of the apoptotic response to targeted anticancer therapeutics. Cancer Discov 5: 475-487, 2015.

This work is licensed under a Creative Commons Attribution-NonCommercial-NoDerivatives 4.0 International (CC BY-NC-ND 4.0) License. 